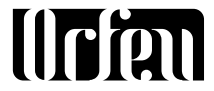

\section{Na Baixa do Sapateiro (Bahia), de Ary Barroso, na interpretação de John Coltrane: a utilização da composição como veículo para a improvisação no jazz modal}

Na Baixa do Sapateiro (Bahia) by Ary Barroso in the interpretation of John Coltrane: The use of the composition as a vehicle for improvisation in modal jazz 


\section{Resumo}

Estudo analítico da interpretação de John Coltrane da música Na Baixa do Sapateiro (Bahia), composição de Ary Barroso. A partir do registro fonográfico, foi realizada uma transcrição pelo autor do presente artigo onde pôde-se observar uma adaptação da composição para a sua utilização como prática de improvisação vinculada ao jazz modal, território explorado pelo saxofonista em sua carreira. Primeiramente, são discutidas questões políticas que contribuíram para a difusão da música brasileira nos Estados Unidos na década de 1940. Em seguida, é abordada a relação de Coltrane com o jazz modal, elucidando as características e salientando a importância da teoria de George Russell (2001) na gênese do estilo. Por fim, trata-se das questões da performance no que diz respeito às adaptações da referida composição, como também, de aspectos da improvisação do saxofonista. Com isso, o trabalho significa uma contribuição aos estudos sobre improvisação, vindo a somar-se na perspectiva da etnomusicologia e das práticas interpretativas em música popular.

Palavras-chave: John Coltrane, improvisação, jazz modal.

\section{Abstract}

Analytic study of John Coltrane's interpretation of the song Na Baixa do Sapateiro (Bahia), composed by Ary Barroso. From phonographic record, we conducted a transcription in which we could observe an adaptation of the composition for use as improvisation practice linked to modal jazz, a territory explored by the saxophonist in his career. Firstly, we discuss the political issues that contributed to the diffusion of Brazilian music in the United States in the 1940s. Next, we address Coltrane's relation to modal jazz, exposing its characteristics and emphasizing the importance of George Russel (2001) in the genesis of said style. Finally, we touch upon matters of performance in regard to the adaptations of the aforementioned composition, as well as aspects of the saxophonist's improvisation. That said, this paper represents a contribution to improvisation studies, adding to the perspective of ethnomusicology and interpretive practices in popular music.

Keywords: John Coltrane, improvisation, modal jazz. 


\section{Introdução}

Na Baixa do Sapateiro foi composta por Ary Barroso em 1938, trata-se de um samba-exaltação que venera as belezas brasileiras com seu caráter saudosista. A composição foi divulgada posteriormente nos Estados Unidos, onde ficou conhecida como Bahia (Baía), por meio, entre outros, do longa-metragem intitulado The Three Caballeros, uma produção da Walt Disney, lançada em 1944, que inclui uma versão em inglês da composição de Barroso como trilha sonora.

A animação traz um enredo cuja proposta é uma apresentação dos inóspitos territórios além E.U.A., tendo como cenário países da América Latina. Com o intuito de mostrar, entre outras questões, as culturas e as belezas brasileiras, o longa está inserido no contexto da Segunda Guerra Mundial (1939-1945), na qual foram instauradas um conjunto de ações políticas cujo objetivo era estreitar as relações internacionais entre os Estados Unidos e os países da América Latina. Nesse sentido, dentre outras nuances, a cultura foi utilizada como um veículo para tal integração.

À primeira vista, essa política contribuiu para a construção de identidades nacionais, o que, inclusive, entra em acordo com a criação de um "sentimento nacional", pretendido pelo governo do então presidente brasileiro Getúlio Vargas (1930-1945) (ver VELLOSO, 2015). Por outro lado, as repercussões desse tipo de diplomacia, que favorece o encontro de diferentes culturas, em certo contexto, podem ser tidas como desfavoráveis, visto as assimetrias de poder.

Tratando da música nesse âmbito, a questão de encontros musicais, ou seja, de uma tomada de elementos musicais de uma cultura por outra, tem sido discutida sob o viés do hibridismo (ver FABRIS, 2005; GANC, 2014), sendo que, esse cruzamento pode gerar algo novo ou não (ver PIEDADE, 2005; 2011). No mundo do jazz, essas apropriações são muito comuns, contudo, o diálogo feito com os elementos musicais de outras culturas tem sido utilizado por parte dos jazzistas no sentido de renovação de sua arte.

Nessa perspectiva, todavia elementos musicais provenientes da América Latina foram validados pelo jazz, mas, especialmente da década de 1940 em diante, esses elementos musicais tornaram-se distinguíveis de outros estilos de jazz (WASHBURNE, 2002). Neste período, o termo Latin Jazz passou a ser utilizado, sendo as qualidades rítmicas a essência dessa investida (WASHBURNE, 2002; GEVERS, 2010). Comumente, é designado o termo latin groove, que é genericamente empregado, a um montante de ritmos de gêneros advindos de diferentes culturas musicais latino-americanas.

A instigante interpretação do quarteto de John Coltrane de Bahia (Na Baixa do Sapateiro), gravada ao final da década de 1950, é um exemplo do emprego do referido groove, o que em certa medida simboliza a latinidade para a cultura jazzista, mas que é algo bem distante dos ritmos do samba encontrados no Brasil. Além dessa peculiaridade, ocorre também um processo de adaptação da referida composição, que passa a ser vinculada a uma linguagem de improvisação, tendo como prerrogativa a utilização de estruturas formais modais, uma das quais o saxofonista investiu nos anos de 1950 e 1960. Trata-se do jazz modal. 
John Coltrane (1926-1967) é considerado um dos grandes inovadores do jazz do século XX. Ele foi obstinado no sentido de um desenvolvimento e de uma evolução de seu estilo pessoal, sendo que suas buscas resultaram em inovações no que diz respeito à inventividade melódica, harmônica e rítmica, que sobremaneira são apropriadas por seus contemporâneos. O saxofonista constituiu as principais vertentes nas quais o jazz se ramificou nas décadas de 1950 e 1960, como o hard bop, o jazz modal (modal jazz) e o jazz de vanguarda (avant-garde). Por fim, Coltrane, em grande escala, contribuiu para a legitimação do jazz enquanto arte.

Ingrid Monson $(1996,1998)$ demonstra um grande interesse na trajetória do saxofonista. Em seu trabalho Saying Something: Jazz Improvisation and Interaction (MONSON, 1996), a autora traz uma análise da interpretação do quarteto de John Coltrane da composição My Favorite Things, comparando-a com a versão original da produção de Rodgers e Hammerstein, de 1959. Monson faz uma relação entre a versão do saxofonista e a tensão étnica que marca os conflitos sociais no período nos Estados Unidos, mostrando-nos que Coltrane denota um caráter irônico em desfavor ao tom racista que assinala a letra da composição e toda a encenação que a produção de 1959 sugere.

Monson (1998), no artigo Oh Freedom: George Russell, John Coltrane, and Modal Jazz, trata de alguns aspectos que dizem respeito ao engajamento do saxofonista no jazz modal. A autora atribui que a gênese do estilo foi impulsionada pela teoria de George Russell, sendo que o jazz modal delineia maior liberdade ao improvisador, pois concentra-se na inventividade melódica sob uma harmonia mais estável. Dessa forma, a improvisação tem menos enfoque na concatenação de acordes, e, na medida em que os músicos exploravam este território, passaram a utilizar uma gama de possibilidades de sonoridades, no que tange a intervalos, arpejos e escalas, não somente a que é montada estritamente em convergência com o acorde do momento harmônico. A pesquisadora faz uma associação entre a proporção de liberdade que o jazz modal tomou com a questão da desigualdade de direitos civis nos Estados Unidos e os movimentos de independência no continente africano. Nesse sentido, o jazz modal simboliza uma liberdade, não somente musical, mas que está relacionada a toda uma gama de questões, como o engajamento político, social, étnico e espiritual. Portanto, essa vertente do jazz passou a ser interpretada como uma espécie de contenda não violenta.

Neste trabalho, demonstro por meio da análise da transcrição de Na baixa do Sapateiro, ou Bahia como é designada na interpretação de John Coltrane, que a referida música brasileira também serviu de aporte interpretativo para que o saxofonista utilizasse os elementos do jazz modal, tendo o músico "adaptado" a composição de Ary Barroso para esta finalidade. A partir daí, lanço mão de uma discussão que diz respeito à relação entre a versão de Coltrane, na qual ele se utilizou de prerrogativas interpretativas que simbolizam a liberdade, e a questão do transnacionalismo e da espiritualidade.

Primeiramente, discuto a relação cultural entre Brasil e Estados Unidos com base nas medidas políticas tomadas durante a Segunda Guerra Mundial cujo objetivo foi de estreitar as relações entre as Américas, compreendendo algumas de suas repercussões. Em seguida, delineio aspectos da gênese do jazz modal, abrangendo a teoria desenvolvida por George Russell, lançada no tratado Lydian Chromatic Approach to Tonal Or- 
ganization (2001), e abordo uma perspectiva da carreira do saxofonista John Coltrane, especificamente sua relação com esse subgênero. Por fim, trago uma análise da referida interpretação, tratando das adaptações da composição, de alguns aspectos da improvisação do saxofonista e de outras questões da performance.

\section{A política pan-americana das décadas de 1930-1940 e algumas de suas repercussões}

A Segunda Grande Guerra (1938-1945) engendrou mudanças sociais, políticas e econômicas, resultando em uma redistribuição territorial e sua vicissitude marcou a história. Em meio aos fatos da guerra, os Estados Unidos, país que estava frente à base Aliada e que foi um dos "vitoriosos" neste horrendo episódio, traçou algumas estratégias que foram concretizadas por medidas político-econômicas, com o intuito de unir as Américas, e de fortalecer assim sua coligação. Portanto, neste período, intensificaram-se as relações entre países da América do Norte e da América Latina, incluindo-se o Brasil, sendo que tal diplomacia previu também o intercâmbio cultural.

Com relação à música neste contexto, Velloso (2015) trata da conjuntura que favoreceu a utilização desta arte como veículo para essa integração, vista como um "pan-americanismo musical" (VELLOSO, 2015: 36). Nesse âmbito, foi criada, em 1938, pela Divisão de Relações Culturais do Departamento de Estado dos E.U.A., a divisão de rádio do Office of the Coordination of Inter-American Affairs (OCIAA), que passou a estimular projetos de produção de conteúdo popular e transmiti-los por meio da radiodifusão em ondas curtas (VELLOSO, 2015: 30).

Em 1939, realizou-se a 1aㅡ Conferência de Relações Internacionais da Área de Música. Na ocasião, o musicólogo Charles Seeger apresentou seu artigo, intitulado The importance to cultural understanding of folk and popular music, propondo estabelecer as relações musicais entre países com ênfase na música folclórica (folk) e popular, sendo fiel aos preceitos democráticos e "incentivar principalmente a comunicação do que é comum entre os homens comuns de todos os países," "pois essas são as únicas técnicas musicais com que a grande maioria das populações pode lidar" (SEEGER, 1940, seç. 6:8,10 apud VELLOSO, 2015:32-33).

Por esse ângulo, as investidas políticas instauradas pelo governo Roosevelt (19331945), que, ao destituir o isolacionismo perante os conflitos hostis contra o Eixo, traçando uma política de boa vizinhança entre alguns de seus vizinhos (latino) americanos, passou a incentivar o intercâmbio musical, sendo que, se seguiu a proposta de Seeger e a música popular foi um importante meio de comunicação nesse sentido. Assim, acentuou-se a circulação e a difusão desses bens simbólicos entre esses países.

No Brasil, a crítica por vezes pondera que essa política se mostrou unidirecional, na medida em que o processo estabeleceu como polo dominante a cultura dos Estados Unidos. Como exemplo, o jornalista e crítico musical José Ramos Tinhorão (1998: 301) critica que a afluência de foxes, blues, swings e boogie-woogies, que adentraram no mercado fonográfico e nos meios de comunicação, causaram um forte impacto na 
música popular do Brasil. O que Tinhorão $(1974,1998)$ atesta é que, como resultado da importação da música norte-americana, houve uma alienação de uma parcela da população brasileira perante a tradição da música popular do país, em favor dos bens simbólicos norte-americanos. Esta crítica está diretamente associada aos músicos da bossa nova, que segundo Tinhorão, utilizaram-se demasiadamente dos elementos do jazz.

Araújo (1999) nos mostra que, além do jazz, tal política de boa vizinhança contribuiu para entrada do bolero no Brasil, não aquele bolero utilizado em larga escala por compositores românticos e do século XX, a exemplo de Ravel, mas o ritmo caribenho que emergiu na América Latina. O fato é que, no Brasil, os sambas-canções passaram a manifestar elementos do bolero, de maneira que, "nos anos de 1940, o bolero brasileiro e o samba-canção eram práticas dificilmente distinguíveis, tanto no que se refere à questão textual, musical e em termos sociais" (ARAÚJO, 1999:47).

Nos Estados Unidos, a política relacionista de Roosevelt também repercutiu. Mesmo antes de ela entrar em vigor, o jazz dialogava com a música proveniente da América Latina, mas, como expõe Washburne (2002), antes da metade da década de 1940, as influências latinas não eram vistas em separado a outros estilos do jazz. Coincidentemente ou não, foi neste período que o termo latin jazz se difundiu, principalmente com as contribuições de nomes como Dizzy Gillespie, Stan Kenton e George Russell. No mundo do jazz, o rótulo é comumente utilizado em um sentido mais genérico, ou seja, para designar uma gama de gêneros musicais provenientes de Cuba, da Colômbia, do Brasil entre outros, e que foram apropriados pelos jazzistas, sendo que, o elemento em destaque dessa investida são as qualidades rítmicas.

Tratando especificamente da música brasileira neste contexto, a exportação do samba para os Estados Unidos resultou em sua fetichização, aquilo que Samuel Araújo (1992: 88 apud BASTOS, 2014: 12) denominou efeito Carmem Miranda. Um exemplo dessa fetichização pode ser visto na produção da Disney, intitulada The Three Caballeros, de 1944. Slobin (2008) faz uma crítica ao filme por sua desconstrução da realidade, da cultura e também por "exotizar" a América Latina. O autor aponta que a produção é o retrato da política de boa vizinhança implantada no período da Segunda Guerra, sendo que o enredo sugere essa intenção. Nele, o personagem Pato Donald representa o "eu" norte-americano que se relaciona com personagens caricaturais, seus vizinhos latinos, os seus convidados, como o José (Zé) Carioca, o "típico" brasileiro (SLOBIN, 2008: 273, 274).

Fora supracitado que a composição de Ary Barroso, Na Baixa do Sapateiro (Bahia), integra-se à trilha sonora do longa-metragem e que a produção foi fundamental para sua divulgação nos Estados Unidos. De acordo com Severiano (1997: 166), a partir dessa produção, a composição se tornou um sucesso, tanto que, no ano de 1945, um milhão de cópias da partitura foram impressas nesse país. Dessa forma, pode-se deduzir que, direta ou indiretamente, o pan-americanismo musical, lançado pela política de Roosevelt nas décadas de 1930 e 1940, permitiu ao saxofonista John Coltrane acesso à referida composição. 


\section{Jazz modal e John Coltrane}

O trompetista Miles Davis foi um dos grandes inovadores do jazz moderno. Em 1958, o músico gravou uma de suas experimentações, expandindo, mais uma vez, as fronteiras de sua linguagem musical. Trata-se da composição Milestones ${ }^{1}$, nome que também designa o título do álbum (DAVIS, 1958), que apontava para a nova direção que o trompetista tomaria. O fato é que Davis estava instigado a renovar seu estilo pessoal. No ano seguinte, em 1959, o músico gravou um disco, intitulado Kind of Blue (DAVIS, 1959), contendo faixas cujas propostas, em certa medida, têm relação com Milestones. O álbum de 1959 foi um dos discos de jazz mais vendidos da história do mercado fonográfico (BARRETT, 2006: 185), sendo reputado por ser a gênese de um novo subgênero do jazz: o jazz modal.

Ron Miller (1996: 9), em seu trabalho Modal Jazz Composition and Harmony, menciona que existem proporções simples e complexas quanto ao conteúdo harmônico que é empregado no jazz modal. Nas mais simples (Modal Simple), a estrutura formal é simétrica e compreende um ou poucos modos ${ }^{2}$. Trata-se das primeiras composições modais no jazz. Nas mais complexas (Modal Complex - Free Form), são utilizados ritmos harmônicos assimétricos e uma forma livre. Vale ressaltar que, genericamente, no jazz modal, exploram-se formas composicionais nas quais se utiliza de concatenações de acordes que evitam a sensação de resolução do trítono.

Exemplos do que Miller chamou de modal simples (Modal Simple) são composições como So What e Milestones, ambas de Miles Davis. Nesta última, a estrutura formal da composição é AABA, que compreende 40 compassos, utilizando-se dos acordes Sol menor com sétima menor (G-7) na sessão $A$, que contém 8 compassos; e Lá menor com sétima menor ( $A-7)$ na sessão $B$, que contém 16 compassos. Em So What, o caso é similar. A estrutura formal é AABA, que compreende 32 compassos, 8 em cada sessão, e são utilizados dois acordes: Ré menor com sétima menor (D-7), utilizado na sessão $A$, e $M i$ bemol menor com sétima menor (Eb-7), utilizado na sessão $B^{3}$.

Davis, ao propor tais qualidades, foi em direção oposta ao que se praticava no jazz em subgêneros em voga na época, como o hard bop. O trompetista tinha a intenção de propiciar maior ênfase no que concerne à inventividade melódica, como ele mesmo atesta em uma entrevista cedida, em 1958, a Nat Hentoff (BARRETT, 2011: 53):

Eu acho que o jazz está começando a ir em uma direção distinta daquela que utiliza-se das concatenações convencionais dos acordes, e retornando a enfatizar

\footnotetext{
1 Monson (1998: 164) menciona que a composição Milestones, não a que foi gravada com o saxofonista Charlie Parker, mas a do disco Milestones (Miles, como é intitulada no álbum), de 1958, é geralmente tomada como a primeira composição modal no jazz. Relevo que, possivelmente, Miles Davis não tenha sido o primeiro jazzista a compor utilizando-se de tal qualidade.

2 Miller, ao utilizar o termo "modo", dá a entender que ele é utilizado em sentido mais estrito em relação aos acordes que compreendem a estrutura formal.

3 Estes são apenas dois exemplos de propostas composicionais concebidas por Miles Davis, nas quais ele se utiliza das prerrogativas modais, angariadas nos álbuns Milestones, mas, principalmente, no Kind of Blue, em que há mais diversidade de composições com características modais. Para uma análise mais detalhada do álbum Kind of Blue, ver Barrett (2006; 2011).
} 
a variação melódica, ao invés da harmônica. Haverá menos acordes, mas infinitas possibilidades sobre o que fazer com eles. Compositores clássicos - alguns deles - têm escrito desta forma durante anos, mas os músicos de jazz raramente o fazem. ${ }^{4}$

Davis, em sua renovação estilística, interessava-se em uma contraproposta aos clichês tonais utilizados em larga escala no jazz. A ênfase na variação melódica, mencionada pelo trompetista, está baseada, também, nas possibilidades que o acorde proporciona ao improvisador, o que Russell (2001) chamou de "polimodalidade vertical" (vertical polymodality), ou seja, uma gama de possibilidades escalares que podem ser utilizadas num acorde individual (MONSON, 1998: 153, 154).

Essas paletas, ou seja, a variedade de escalas $/ \operatorname{modos}^{5}$ nas quais o músico pode explorar diversas possibilidades de sonoridade, foram sistematizadas por George Russell (2001) e lançadas no livro Lydian Chromatic Approach to Tonal Organization, publicado em 1953. Segundo Moore (1998), a obra de Russell foi o primeiro trabalho teórico a ser publicado sobre a tradição jazzista. A teoria de Russell foi formulada segundo suas experiências musicais, resultado de sua percepção, e, suas ideias passaram a influenciar o mundo do jazz (MONSON 1998: 155).

Russell (2001) trata de uma concepção de improvisação desenvolvida de acordo com uma organização tonal fundamentada no modo lídio. Em suas elucidações, o autor destaca que a escala jônia e a lídia apresentam comportamentos distintos com relação à tonalidade. A escala jônia, simétrica, representa a horizontalidade, pois encerra os estados de tensão e relaxamento causados pela força ativa de atração para os acordes montados sob o primeiro grau maior e o sexto grau menor desta escala, os centros tonais. Este fenômeno ocorre linearmente em tempo contínuo. Já a escala lídia apresenta uma força passiva em relação à tonalidade, não havendo atração para a tônica. Esta escala, portanto, não busca a estabilidade, mas sim visa destacar o efêmero.

Em seu tratado, Russell traz uma listagem de escalas/modos e reconhece três abordagens distintas de improvisação: horizontal, vertical e supravertical. Em suma, essas perspectivas se distinguem, de forma que: a) a abordagem horizontal tem um estado ativo em relação à tonalidade, pois encerra o fenômeno de tensão-resolução; b) a abordagem vertical tem um estado passivo em relação à tonalidade, uma vez que possui como prerrogativa a valorização das concatenações harmônicas; c) a abordagem supravertical tem um estado ora de neutralidade, ora de conciliação em relação à tonalidade.

Com suas elucidações, Russell abre um novo leque de possibilidades. Sobremaneira, a concepção do jazz modal está vinculada à teoria, ou como também é conhecida "O Conceito" (The Concept) (MONSON, 1998: 154), desenvolvido por George Russell.

\footnotetext{
4 Do inglês. "I think a movement in jazz is beginning away from the conventional string of chords, and a return to emphasis on melodic rather than harmonic variation. There will be fewer chords but infinite possibilities as to what to do with them. Classical composers-some of them - have been writing this way for years, but jazz musicians seldom have". Tradução própria.
} 
Moore (1998) versa sobre essa relação. Este autor cita que Nisenson, um dos biógrafos de Miles Davis, menciona que "Miles Davis revelou que foi Russell quem mostrou à Davis como compor e improvisar no que rotulou-se jazz modal"6 (MOORE, 1988: 15). Sobretudo, a intenção do trompetista, além de uma mudança de estilo, no que diz respeito à sonoridade (indo do hard bop cuja sonoridade é mais "pesada" do álbum Milestones, para uma mais branda e suave, como pode ser notado no Kind of Blue), foi também a de enfatizar as paletas com as quais se somam infinitas possibilidades inventivas.

John Coltrane, após um período trabalhando com o pianista Thelonious Monk, volta a integrar o grupo liderado por Miles Davis, em sua fase de novas explorações com harmonias modais. O saxofonista relata essa circunstância em entrevista à revista DownBeat nos anos de 1960 (BAIR, 2003: 27):

Após deixar Monk, eu voltei a trabalhar com um outro grande músico, Miles. Nessa volta, esta vez ficaria até que formasse meu próprio grupo [...], eu encontrei Miles no meio de outro estágio de seu desenvolvimento musical. [...]. Ele estava interessado no que os acordes podiam proporcionar. ${ }^{7}$

O saxofonista participou, entre outras, das gravações dos álbuns Milestones, de 1958, e Kind of Blue, de 1959. De certo, essas experiências contribuíram para que o saxofonista desenvolvesse sua própria investida no jazz modal, que veio a servir como fundamento para diversas de suas composições, a exemplo de Impressions cuja estrutura formal é idêntica à composição So What, de Miles Davis. Como tudo indica, Miles foi importante para que Coltrane também constituísse o subgênero. Monson menciona que o próprio Russell também influenciou Coltrane nesse período (ver MONSON 1998: 157).

No tocante à improvisação no jazz modal, Monson (1998: 150) reconhece que há relativamente uma maior liberdade de escolhas de notas em relação à harmonia mais estática; dessa maneira, há uma maior liberdade quanto à inventividade melódica. A autora aponta que, na improvisação no jazz modal, "utilizando os termos de Russell, passou de uma orientação 'tonal' horizontal para supravertical, na medida em que os músicos expandiram as fronteiras das composições modais" (MONSON, 1998: 159) ${ }^{8}$. Em termos gerais, isso significa que os improvisadores não utilizam o modo montado sob a relação escala-acorde de forma estrita em seus solos (KERNFELD,1981 apud BARRETT, 2011: 53). Dessa forma, utiliza-se de uma ampla gama de intervalos, escalas e arpejos, relacionados ou distantes do centro modal ou o acorde do momento.

Monson (1998) faz uma relação dessa qualidade da improvisação, na qual se expandem as barreiras da tonalidade, denotando metaforicamente maior liberdade, com as tensões que marcam os conflitos sociais, étnicos e políticos que Coltrane vivenciou

\footnotetext{
6 Do inglês. "Miles Davis have revealed that it was Russel who showed Davis how to compose and improvise what became labeled 'modal jazz'". Tradução própria.

7 Do inglês. "After leaving Monk, I went back to another great musical artist, Miles. On returning, this time to stay until I formed my own group a few months ago, I found Miles in the midst of another stage of his musical development. There was one time in his past that he devoted to multi-chorded structures. He was interested in chords for their own sake." Tradução própria

8 Do inglês. "To use Russell's terms, there was a move from horizontal to supravertical tonal organization as performers expanded the boundaries of modal tunes." Tradução própria.
} 
em seu próprio tempo. Nesse sentido, Coltrane "enfatiza o poder da música de desmantelar categorias como raça, cor, e nação" (MONSON 1998: 156). Portanto, essa ideologia cujo ápice se deu na década de 1960 valida a investida e o interesse de Coltrane na música e religião de outras nações, um transnacionalismo, como também está ligada a uma contenda, na qual a música, em especial o jazz modal, é o principal meio de denúncia e libertação. Contudo, "o jazz modal como símbolo de liberdade se tornou um tropo familiar" (BARRETT, 2006: 195).

\section{Análise}

O disco Bahia de John Coltrane, lançado em 1965 pelo selo Prestige (COLTRANE, 1965), é uma compilação de gravações que datam de 1958, período no qual trabalhava com Miles Davis, ao mesmo tempo fazia gravações paralelas às que realizava com o trompetista. Como mencionado, a composição de Ary Barroso, intitulada Na Baixa do Sapateiro, na versão do saxofonista é nomeada Bahia, nome que também é designado ao álbum.

Para o que pretende esta análise, foram selecionadas mais duas gravações de $\mathrm{Na}$ Baixa do Sapateiro, com o propósito de estabelecer uma comparação com a versão de John Coltrane. A primeira, é a versão de Carmen Miranda (MIRANDA, 1938), lançada no mesmo ano em que fora composta (1938). A outra é a trilha sonora da produção da Disney, de 1944, uma versão em inglês gravada na voz de Ray Gilbert, com direção musical de Charles Wolcott (WOLCOTT, 1944). Curiosamente, nessa versão de 1944, Bahia está grafada incorretamente: escreveu-se "Baía", possivelmente pelo motivo de uma preocupação com a pronúncia da palavra.

Com relação à estrutura formal, na versão de Coltrane, adaptou-se a composição excluindo boa parte de sua estrutura, recortando-a numa forma que compreende 16 compassos, que possuem 3 acordes: Dó menor com sétima menor (C-7); Si bemol com sétima maior (Bb7M); Si bemol menor com sétima menor (Bb-7) (fig. 1). O recorte exclui grande parte do tema ${ }^{9}$ composto por Ary Barroso; além disso, o saxofonista concebeu sua própria interpretação das melodias, em especial os compassos 13 a 15 do esquema que segue (fig.1). Nesse trecho, há uma variação da proposta melódica, comparando-a com as outras duas versões supracitadas. A figura a seguir (fig. 1) representa a lead-sheet da versão de Coltrane: 

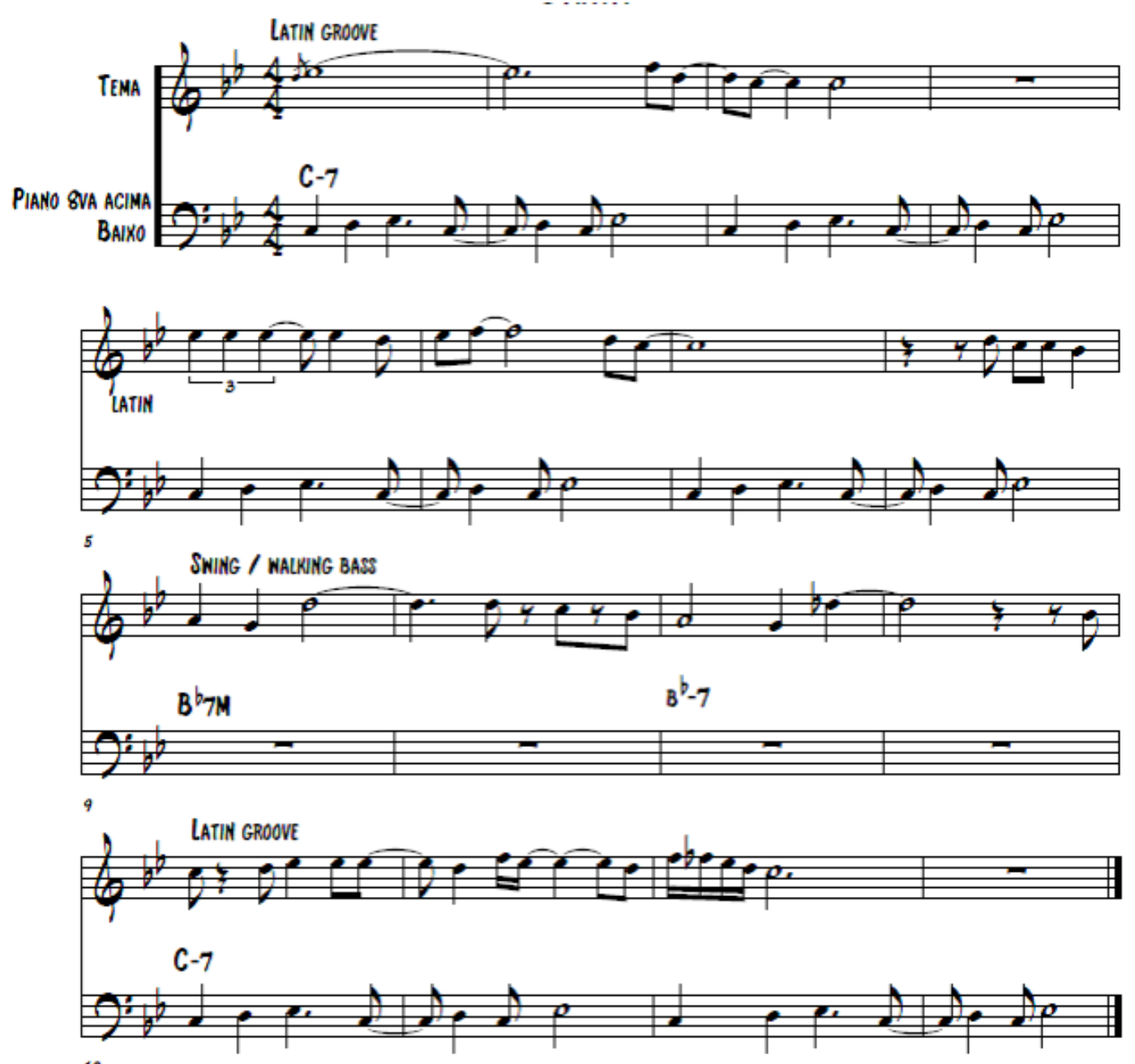

Fig. 1. Lead-sheet de Bahia (Na Baixa do Sapateiro), na interpretação de John Coltrane. Representação da estrutura formal (chorus), do tema, da harmonia, do ostinato empregado no baixo e no piano e da estrutura rítmica empregada na bateria.

No que diz respeito ao aspecto harmônico, ao comparar a versão do saxofonista com a de Miranda, nota-se que o acorde de Dó menor com sétima menor (C-7), dos compassos 1 a 8 da lead-sheet (fig.1), vem a substituir o acorde mixolídio, no caso Fá maior com sétima menor $(F 7)^{10}$, que em seguida resolveria em Si bemol com sétima maior (Bb7M). Outra rearmonização, compete ao acorde de Dó menor com sétima menor (C-7), dos compassos 13 a 16 da lead-sheet (fig. 1), que foi rearmonizado no sentido de substituir o que, na versão de Miranda, caracteriza uma zona de dominante secundária, que polariza o acorde de Fá maior com sétima menor (F7). Nesses quesitos, a versão de Wolcott, a que foi utilizada na animação da Disney, é similar à de Miranda, mas está em outra tonalidade, na mesma da versão de Coltrane.

Nota-se que nas versões de Miranda e Wolcott são flagradas regiões modais - o acorde de Fá maior com sétima menor (F7), que é substituído por Dó menor com sétima menor (C-7) na versão de Coltrane (compassos 1 a 8 da fig.1), é uma região modal. 0 
acorde de Si bemol menor com sétima menor (Bb-7) (compasso 11 da fig. 1) caracteriza-se como um acorde empréstimo modal e está presente nas três versões - mas cabe ressaltar também o caráter tonal dessas versões. $O$ fato é que Coltrane rearmoniza a composição, de forma a estruturá-la, evitando o que lhe proporcionaria o caráter tonal e transformando-a em estritamente modal.

No que diz respeito à qualidade rítmica das interpretações, a versão de Coltrane se assemelha à de Gilbert quanto à unidade de compasso, pois está em compasso quaternário, o quatro por quatro, diferentemente da versão de Miranda, que se encontra em compasso binário, o dois por quatro, tradicionalmente a unidade de compasso do samba.

$\mathrm{Na}$ versão do saxofonista, são postas duas regiões que são contrastantes. Nos compassos 1 a 8 e 13 a 16 (fig. 1), o baterista Art Taylor emprega o que genericamente no mundo do jazz se denomina latin groove ${ }^{11}$. Nos compassos 9 a 12, Taylor utiliza a condução tradicional do jazz com o walking bass articulado pelo baixista Paul Chambers. Como demonstrado na lead-sheet (fig. 1), nos compassos 1 a 8 e 13 a 16, ocorre um ostinato empregado pelo contrabaixo e pelo piano que é tocado com o latin groove. Tal ostinato está presente em todas as gravações supracitadas, porém, em diferentes contextos harmônicos, e na versão de Coltrane há uma antecipação em colcheia da nota Dó, no último tempo dos compassos ímpares $(1,3,5,7,13,15)$ (fig. 1).

No que concerne à improvisação do saxofonista, a estrutura formal, ou seja, a configuração representada pela lead-sheet (fig. 1) é mantida ao longo do solo de Coltrane. Assim, tanto o ostinato do contrabaixo e do piano com o chamado latin groove, quanto a condução tradicional do jazz (swing) articulada pelo baterista Taylor com o walking bass empregado por Chambers são repetidos durante o solo do saxofonista.

Reiterando a ideia de liberdade que o jazz modal proporciona, Boothroyd (2010: $59,60)$ nos mostra que pelo fato de que no jazz modal, em certa medida, não há preocupação com o ritmo harmônico, pois há poucos acordes na estrutura formal, isto, por fim, delineia linhas melódicas mais fluidas, no sentido de que a liberdade também está vinculada à questão rítmica das frases. Neste quesito, Coltrane, como aporte, emprega trechos escalares rápidos, em grande parte dos casos sem articulação (legato).

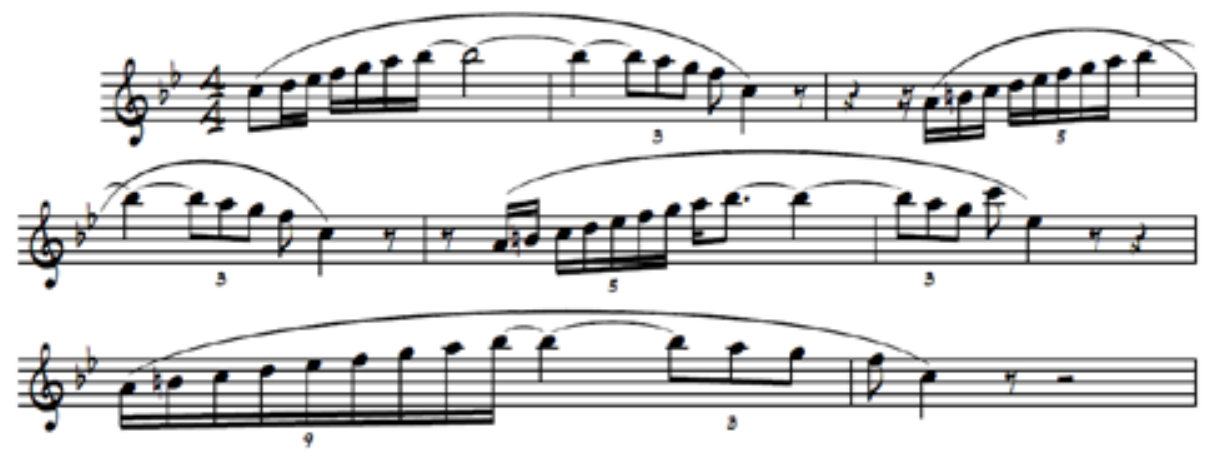

Fig. 2. Trecho inicial do primeiro chorus da improvisação de John Coltrane em Bahia. Compassos 17 a 24. 11 Outros nomes são utilizados, por parte dos jazzistas, para designar os ritmos provenientes da América Latina, alguns mais genéricos
como Latin Rhythm; e outros mais específicos como bossa nova e clave. 
O exemplo anterior (fig. 2) representa um trecho do primeiro chorus da improvisação do saxofonista, no qual ele utiliza uma escala ascendente cuja nota alvo é Si bemol, deslocada ritmicamente ao longo dos compassos.

No trecho, pode ser notado que Coltrane se mantém próximo ao modo sugerido pela harmonia, no caso Dó menor, empregando o modo montado sob o sexto grau da escala lídia (ver RUSSEL, 2001), ou seja, o modo dórico, que possui a sexta maior. Este modo é utilizado quase inteiriço, exceto pela nota Si natural, a sétima maior de Dó, verificada nos compassos 19, 21 e 23 do exemplo anterior (fig. 2). De fato, o saxofonista utiliza esta nota ao longo de sua improvisação, inclusive sustentando-a em alguns trechos.

Na medida em que Coltrane desenvolve seu solo, utiliza-se de escalas que se distanciam do centro modal, o acorde do momento. Um exemplo pode ser conferido na transcrição que segue (fig. 3). No contexto harmônico onde está implícito o acorde de Dó menor com sétima menor (C-7), Coltrane emprega notas fora da escala (outside). Refiro-me às semicolcheias do compasso 30 e às colcheias em quiáltera de sete notas do compasso seguinte. A sequência melódica compreende as notas Fá (quarta justa); Mi bemol (terça menor); Ré bemol (nona menor); Dó (fundamental); Si natural (sétima maior); Lá (décima terceira) (fig. 3).

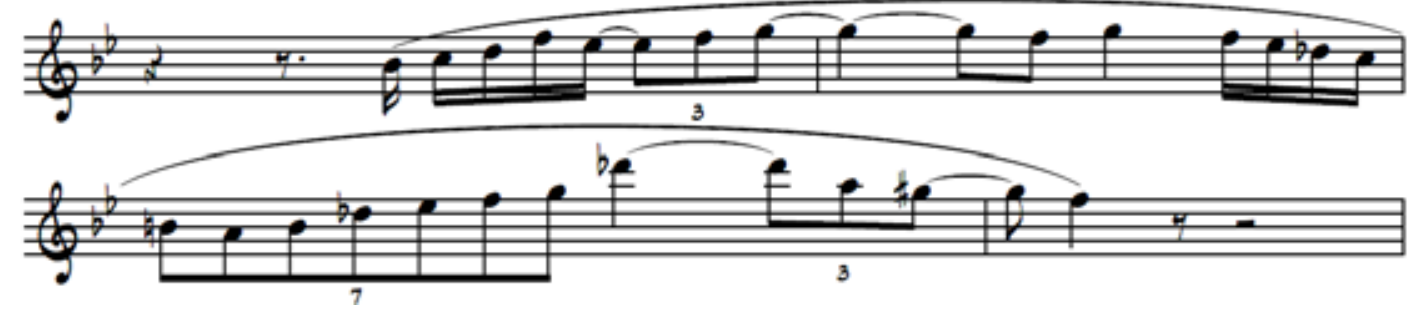

Fig. 3. Trecho final do primeiro chorus da improvisação de John Coltrane em Bahia. Compassos 29 a 32.

Os dois exemplos anteriores (Figs. 2 e 3) caracterizam a abordagem supravertical, pois é montada uma relação ora de conciliação, como é o caso analisado do exemplo na figura 2, ora de neutralidade, como é o caso exemplificado na figura 3, em relação à "tônica modal", no caso Dó menor.

\section{Conclusão}

A improvisação no jazz muitas vezes é tomada como um símbolo de liberdade. Essa metáfora está associada ao domínio da técnica e à "extrapolação" da tonalidade, como também ao contexto sociopolítico, no qual a segregação racial marca a tensão em que os músicos norte-americanos viveram em seu próprio tempo. No jazz modal, enfatizou-se a inventividade melódica, principalmente pelo motivo da utilização de uma harmonia mais estática; sobremaneira, utilizou-se de uma gama de sonoridades no que diz respeito a escalas, arpejos e intervalos, não somente aqueles montados em conver- 
gência ao acorde do momento, o que Russell denomina abordagem supravertical.

A interpretação de Na Baixa do Sapateiro, ou melhor, Bahia, por parte do quarteto de John Coltrane insere-se neste contexto. Com a análise, pôde-se observar que a composição de Ary Barroso foi adaptada pelo saxofonista, sendo utilizada como veículo de novas explorações, o que viria a ser denominado jazz modal. Na estrutura formal, que foi reduzida e na qual grande parte do tema não foi utilizado, valeu-se de poucos acordes e evitou-se a sensação de resolução do tritono. Essa modelagem proporcionou ao saxofonista o emprego de elementos musicais pelos quais estava interessado, de forma que a improvisação do saxofonista foi desenvolvida a partir da abordagem supravertical, isto é, em momentos de conciliação, em outros de neutralidade em relação ao centro modal. Por fim, tem-se uma nova versão da composição, totalmente inusitada e instigante.

O saxofonista, em sua busca pela espiritualidade interessou-se também em religiões e culturas musicais de outras regiões do globo, como a África e a Índia, incluindo-se neste âmbito o Brasil. O fato é que, além da interpretação da composição de Ary Barroso analisada neste artigo, Coltrane tem uma composição que leva o nome da capital do país, Brasília (Brazilia), o que ressalta esse interesse. A transnacionalidade, nesse caso, insere-se como uma consciência que conecta nuances como as injúrias étnicas - tais como ele presenciou em seu próprio tempo com outras - nas quais estão engendradas questões como a opressão, a dominação, o racismo e as formas de exclusão.

John Coltrane deixou seu legado, principalmente no que se refere às suas inovações harmônicas e melódicas. Pôde-se notar que, na década de 1950, o saxofonista apresentava um estilo bem à frente do seu tempo. Contudo, suas descobertas musicais e seu estilo pessoal continuam influenciando músicos por todo o mundo.

\section{Bibliografias}

ARAÚJO, Samuel. The Politics of Passion: The impact of Bolero on Brazilian Musical Expression. Yearbook for Tradicional Music, Vol. 31. 1999. Disponível em http://www. jstor.org/stable/767972 acessado em 25/05/2016

Acoustic Labour in the Timing of Everyday Life: A critical history of samba in Rio de Janeiro, 1917-1990. Tese (Doutorado em Musicologia). University of Illinois at Urbana Champaign. Urbana (EUA). 1992. Em BASTOS, Rafael josé de Menezes. Para uma antropologia histórica da música popular brasileira. Antropologia em Primeira Mão. Artigo. UFSC. Florianópolis. SC. 2014.

BAIR, Jeff. Cyclic Patterns in John Coltrane's Melodic Vocabulary as Influenced by Nicolas Slonimsky's Thesaurus os Scales and Melodic Patterns: An Analysis of Selected Improvisations. Dissertation (Doctor of Musical Arts). University of North Texas. 2003.

BARBOSA, Márcia Helena Saldanha e GAGLIETTI, Mauro: A Questão da Hibridação Cultural em Nestor Canclini. Comunicação. Intercom - Sociedade Brasileira de Estudos Interdisciplinares da Comunicação VIII Congresso Brasileiro de Ciências da Comunicação da Região Sul - Passo Fundo - RS. 2007. 
BARRETT, Samuel. Kind of Blue and the economy of modal jazz. Popular Music. Vol. 25/2. University of Cambridge. 2006

Classical Music, Modal Jazz and the making of Kind of Blue.

Dutch Journal of Music Theory, vol. 16. N. 1. 2011

BOOTHROYD, Myles. Modal Jazz and Miles Davis: George Russell's Influence and the Melodic Inspiration behind Modal Jazz, Nota Bene: Canadian Undergraduate Journal of Musicology: Vol. 3: Iss. 1, Article 5. 2010. http://ir.lib.uwo.ca/notabene/vol3/iss1/5 acessado em 01/09/2016

FABRIS, Bernardo Vescovi. Catita de K-Ximbinho e a interpretação do saxofonista Zé Bodega: aspectos híbridos entre o choro e o jazz. Belo Horizonte: UFMG, 2005. (Dissertação de Mestrado).

GANC, David. Fricção e Hibridismo na música de Nivaldo Ornelas. Artigo. Anais do III SIMPOM 2014 - Simpósio Brasileiro Pós-Graduação em Música. 2014.

GEVERS, Jeroen. Reinterpreting Bossa Nova: Instances of Translation of Bossa Nova in the United States, 1962-1964. Thesis (degree of Master of Arts in Musicology) Utrecht University. 2010.

KERNFELD, Barry D. Adderley, Coltrane, and Davis at the Twilight of Bebop: The Search for Melodic Coherence (1958-59)', Ph.D. Dissertation, Cornell University, 1981, 2 vols., vol. I, 155-174. Em BARRETT, Sam. Classical Music, Modal Jazz and the making of 'kind of blue' dutch journal of music theory, volume 16, number 1. 2011.

MILLER, Ron. Modal Jazz Composition and Harmony. Vol. 1. Advanced Music. 1996.

MONSON, Ingrid T. Saying Something: Jazz Improvisation and Interaction. Chicago: University of Chicago Press, 1996.

"Oh Freedom: George Russell, John Coltrane, and Modal Jazz." In In the Course of Performance: Studies in the World of Musical Improvisation, edited by Bruno Nettl with Melinda Russell. Chicago: University of Chicago Press, 1998. 149-168.

MOORE, Robert. George Alan Russell: Jazz's First Theorist. Trotter Review: Vol. 2: Iss. 2, Article 5. 1988. Disponível em http://scholarworks.umb.edu/trotter_review/vol2/ iss $2 / 5$ acessado em 01/09/2016

PIEDADE, Acácio Tadeu de Camargo. Jazz, música brasileira e fricção de musicalidades. Campinas: Opus, Revista da ANPPOM, n 11, p. 197 a p. 207, 2005.

Perseguindo fios da meada: pensamentos sobre hibridismo, musicalidade e tópicas. Per Musi, Belo Horizonte, nํ 23, p.103-112, 2011.

RUSSELL, George. Lydian Chromatic Concept of Tonal Organization - Concept Publish Company, 40 Shepard Street; Cambridge, MA 02138, 2001.

SCHOENBERG, Arnold. Fundamentos da Composição Musical: Tradução de Eduardo Seincman. $3^{\circ}$ ed. São Paulo. Ed. da Universidade de São Paulo. 2008.

SEEGER, Charles. Music as a factor in cultural strategy in America. Bulletin of the American Musicological Society, n.3 1939 em VELLOSO, Henrique Soares. Aquarelas Musicais das Américas: Projetos de nação nas performances radiofônicas de Radamés Gnattali e Alan Lomax (1939 - 1945) Tese (doutorado em Música-Etnomusicologia). 
UFRG. 2015. p. 32-33

SLOBIN, Mark. Motion Pictures Music: History and Criticism. Weslyean University Press. Middletown. 2008

TINHORÃO, José Ramos. História da música popular brasileira. São Paulo: Editora 34. 1998. 365

Pequena História da Música Popular Brasileira: Da Modinha à Canção de Protesto. ED. Vozes. Petrópolis. RJ. 1974.

VELLOSO, Henrique Soares. Aquarelas Musicais das Américas: Projetos de nação nas performances radiofônicas de Radamés Gnattali e Alan Lomax (1939 - 1945) Tese (doutorado em Música-Etnomusicologia). UFRGS. 2015.

WASHBURNE, Christopher. Latin Jazz: the other jazz. Current musicology, n. 71-73 (Spring 2001-2002) Columbia University. New York. 2002.

6. Discografia

COLTRANE, John. Bahia. Prestige. New Jersey. PRLP 7353, 1965.

COLTRANE, John. Blue Trane. Blue Note. New Jersey. BLP 1577. 1958.

DAVIS, Miles. Kind of Blue. Columbia. New York. CL 1355. 1959.

DAVIS, Miles. Milestones. Columbia. New York. CL 1193. 1958.

MIRANDA, Carmen. Carmen Miranda com a Orquestra Odeon: Na Baixa do Sapateiro. Odeon. Rio de Janeiro. 11667-B. 1938

WOLCOTT, Charles. Charles Wolcott and his Orquestra: Baía (Na Baixa do Sapateiro). Side 3. Decca. New York. L 3297. 1944. 